\title{
Development of an Analytical Method for the Determination of Photoinitiators Used for Food Packaging Materials with Potential to Migrate into Milk
}

\author{
A. Sanches-Silva, ${ }^{*}$ S. Pastorelli,† J. M. Cruz, ${ }^{*}$ C. Simoneau, $\dagger$ I. Castanheira, $\neq$ and P. Paseiro-Losada*1 \\ *Department of Analytical Chemistry, Nutrition and Food Science, Faculty of Pharmacy, University of Santiago de Compostela, E-15782 Spain \\ †Joint Research Centre (JRC), Ispra, Italy \\ $\ddagger$ National Institute of Health Dr. Ricardo Jorge, Lisbon, Portugal
}

\begin{abstract}
Photoinitiators are used in the curing process during UV printing of food carton labels. The alarm concerning the detection of a photoinitiator, 2-isopropyl thioxanthone (ITX), in food samples packed with cartons printed with UV-cured inks has focused the attention of legislative authorities on the potential migrants from packaging inks into foods. For this reason it is very important to carry out analytical methods for the detection of those compounds in food as potential migrants from packaging. The aim of the present work was to develop a multimethod for the analysis of 6 photoinitiators in milk. The selected photoinitiators were Irgacure 184, benzophenone, Irgacure 651, Irgacure 907, Quantacure ITX, and Quantacure EHA (2-ethylhexyl4-dimethylaminobenzoate). Milk (10 mL) extraction was carried out by using ammoniac and hexane. The supernatant was evaporated and the residue was redissolved with acetonitrile. Then, the extract was analyzed by HPLC-UV. Calibration lines were carried out over the concentration range of 0.1 to $10 \mathrm{mg} / \mathrm{L}$. The calibration data presented high correlation coefficients $(>0.9999)$. Mean recoveries $(\mathrm{n}=6)$ of the 6 photoinitiators were $83.4 \%$ (residual standard deviation $=2.3 \%$ ) at $0.5 \mathrm{mg} / \mathrm{kg}$ and $81.0 \%$ (residual standard deviation = $4.6 \%$ ) at $1 \mathrm{mg} / \mathrm{kg}$. Several milk samples and their respective packaging cartons were analyzed. Results were confirmed by HPLC-mass spectrometry.
\end{abstract}

Key words: food packaging, photoinitiator, infant formula, isopropyl thioxanthene

\section{INTRODUCTION}

Food industry and food packaging manufacturers as well as organizations responsible for legislation concern

Received October 30, 2007.

Accepted November 21, 2007.

${ }^{1}$ Corresponding author: qnpaseir@usc.es about the safety of foodstuffs especially baby food, because young children consume a larger number of beverages (like milk and fruit juices) in small-volume packages that could increase their potential dietary exposure to undesirable chemical substances. In line with this, a recent food alert related to the photoinitiator (PI) isopropyl thioxanthene (ITX) has provoked concern in this field. The Rapid Alert System for Food and Feed (RASFF) issued the alert, and the European Food Safety Authority (EFSA) carried out a risk assessment on ITX at the request of the European Commission (RASFF, 2005). In November 2005, EFSA declared that "on basis of the very limited data available today, the presence of ITX in food could be considered undesirable but it is not likely to present a health risk at the levels reported" (EFSA, 2005a). This press statement indicates that the ITX toxicity evidence is not fully convincing and there is a need to evaluate its toxicity for suitable risk evaluation and to guarantee consumer protection.

In December 2005, the Scientific Panel on Food Additives, Flavourings, Processing Aids and Materials in Contact with Food, by request of the European Commission, published their opinion related to 2-ITX and 2ethyl(hexyl-4-dimethylaminobenzoate) (EHDAB) and concluded that there is little information about ITX genotoxicity, although 2 in vivo studies have shown clearly negative results. Moreover, infants fed exclusively with formulas packed in UV-printed cartons are more exposed to ITX and EHDAB (EFSA, 2005b).

As a consequence of this alert, over 30 million liters of ready-to-feed infant formula was recalled by producers in Portugal, Italy, France, and Spain in November 2005 (Morlock and Schwack, 2006; Sun et al., 2007).

Isopropyl thioxanthene is a PI that can be found in foodstuffs as result of the contact of the external printed face of packaging with the inner face (nonprinted), the so-called setoff effect (Morlock and Schwack, 2006; Rothenbacher et al., 2007). It also can pass through the packaging if no barrier is applied (Sagratini et al., 2006). Because milk is a fatty food, free ITX (non-poly- 
Table 1. Methods found in the literature to analyze photoinitiators ${ }^{1}$

\begin{tabular}{|c|c|c|c|c|}
\hline Reference & Matrix & Extraction procedure & $\begin{array}{l}\text { Chromatographic } \\
\text { method }\end{array}$ & $\begin{array}{c}\text { Detection limit (LD)/ } \\
\text { Quantification limit (LQ) }\end{array}$ \\
\hline \multirow[t]{2}{*}{$\begin{array}{l}\text { Morlock and Schwack, } \\
2006\end{array}$} & Milk, yogurt, and fat & $\begin{array}{l}\text { Milk-based matrixes: } \\
\text { Accelerated solvent extraction } \\
\text { with cyclohexane and ethyl } \\
\text { acetate }\end{array}$ & $\begin{array}{l}\text { HPLC coupled } \\
\text { with MS } \\
\text { (HPTLC) } \\
\text { (poor recovery) }\end{array}$ & $\begin{array}{l}\mathrm{LD}=64 \mathrm{pg} \\
(32 \mathrm{ng} / \mathrm{mL})\end{array}$ \\
\hline & & $\begin{array}{l}\text { Margarine and soybean oil: } \\
\text { Extraction with acetonitrile }\end{array}$ & & $\begin{array}{l}\text { Butter } \\
\mathrm{LD}=1 \mu \mathrm{g} / \mathrm{kg} \\
\mathrm{LD} \text { with ESI } / \mathrm{MS}=128 \mathrm{pg}\end{array}$ \\
\hline Sagratini et al., 2006 & Fruit juices & $\begin{array}{l}\text { Pressurized liquid extraction } \\
\text { with acetone:hexane }(50: 50)\end{array}$ & LC-MS & $\begin{array}{l}\mathrm{LD}=3 \mu \mathrm{g} / \mathrm{L} \text { single quadrupole } \\
\mathrm{LD}=3 \mu \mathrm{g} / \mathrm{L} \text { ion trap } \\
\mathrm{LD}=0.01 \mu \mathrm{g} / \mathrm{L} \text { triple quadrupole }\end{array}$ \\
\hline Sun et al., 2007 & $\begin{array}{l}\text { Milk, juice, tea, } \\
\text { and yogurt }\end{array}$ & $\begin{array}{l}\text { Foodstuffs: } \\
\text { Extracted with acetonitrile:water } \\
\text { (60:40, vol/vol) and further } \\
\text { cleanup and preconcentration } \\
\text { using solid-phase extraction }\end{array}$ & LC-MS-MS & $\begin{aligned} \mathrm{LD} & =0.15 \mu \mathrm{g} / \mathrm{kg} \\
\mathrm{LQ} & =0.05 \mu \mathrm{g} / \mathrm{kg}\end{aligned}$ \\
\hline
\end{tabular}

${ }^{1}$ HPTLC = high-performance thin layer chromatography; DAD = diode array detector; LC = liquid chromatography; FLD = fluorescence detector; ESI = electrospray ionization.

mer-bonded) is easily soluble in it due to its high lipophilicity. In the case of orange juice, orange fiber could incorporate photoinitiators and contaminate the juice (Sagratini et al., 2006).

Photoinitiators are substances used to catalyze the UV curing process of inks and they can be applied to paper, paperboard, or plastic (Morlock and Schwack, 2006; Bradley, 2006a,b, 2007). This type of ink presents a great advantage because it does not contaminate food with organic solvent residues from the printing process. However, the main constituents of this type of ink (acrylates and PI) can contaminate foods (Bradley, 2006a; Rothenbacher et al., 2007).

It is the responsibility of the packaging industry to ensure the safety of the packaging. As a result, although inks are not specifically covered by European Union legislation, it is stated in the Framework (European Union, 2004) that packaging shall keep the integrity of the food and shall not endanger the safety by transferring their constituents into foodstuffs. There is a need for analytical methods to determine the chemicals in foodstuffs as a result of transference from packaging (e.g., monomers, starting substances, solvents, ink components). As far as we know, there are few analytical methods available for the determination of ITX in milk (Morlock and Schwack, 2006; Rothenbacher et al., 2007; Sun et al., 2007) and just 2 are multimethods that determine PI (Papilloud and Baudraz, 2002a,b) (benzophe- none, Irgacure 184, benzylketal BDK, Irgacure 907, Quantacure ITX) in aqueous simulants (see Table 1). The aim of this paper was to develop a multimethod for the detection and quantification of 6 PI (including ITX) in dairy products and their respective packages. The other 5 PI, besides ITX, were chosen because they may be used to substitute ITX as catalysts of photopolymerization. In the present work, milk extraction was carried out by traditional organic solvent extraction, and an HPLC-diode array detector method was developed for quantification. Confirmation was performed by liquid chromatography-MS time of flight. The method was applied to infant formulas, their respective packaging, and other dairy product packaging from industry sources and local supermarkets.

\section{MATERIALS AND METHODS}

\section{Chemicals, Standards, and Samples}

Six PI were chosen: Irgacure 184 [CAS no. 947-19-3; methanone (1-hydroxycyclohexyl)phenyl-(9CI)]; benzophenone [CAS no. 119-61-9; metanone diphenyl- (9CI)], Irgacure 651 [CAS no. 24650-42-8; ethanone, 2,2-dimethoxy-1,2-diphenyl-(9CI)], Irgacure 907 [CAS no. 71868-10-5; 1-propanone, 2-methyl-1-[4-(methylthio)phenyl]-2-(4-morpholinyl-(9CI)], Quantacure ITX, a mixture of 2 isomers [CAS no. 5495-84-1 and 84846-86- 


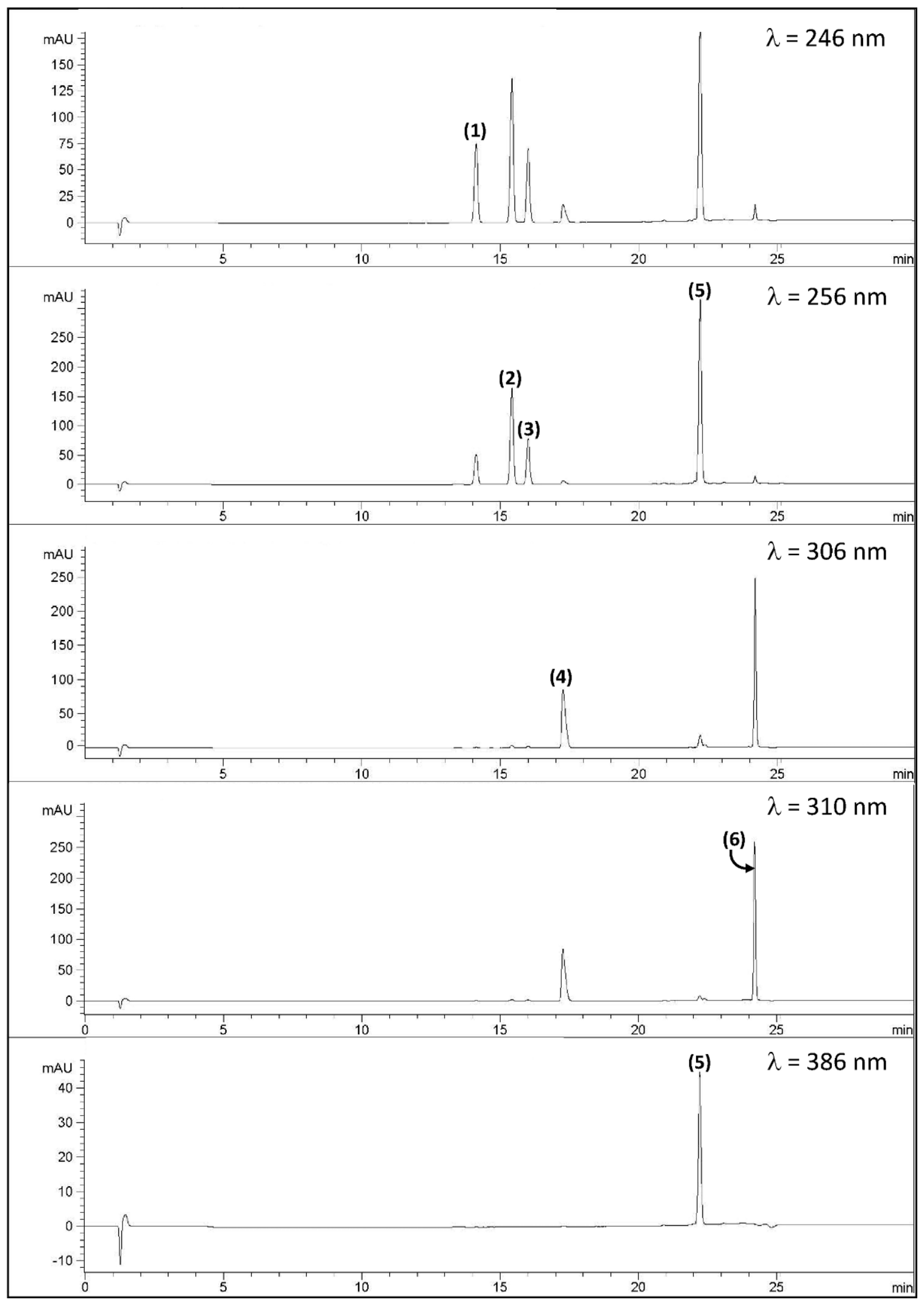

Figure 1. High-performance liquid chromatogram of a standard $(1 \mathrm{mg} / \mathrm{kg}) . \mathrm{mAU}=$ milli-arbitrary units. Peaks: $1=$ Irgacure $186 ; 2=$ benzophenone; 3 = Irgacure 651; 4 = Irgacure 907; 5 = Quantacure ITX; 6 = Quantacure EHA. 
Table 2. Mean recovery (and residual SD, RSD) for the 6 photoinitiators $(\mathrm{PI})$ at 0.5 and $1 \mathrm{mg} / \mathrm{kg}(\mathrm{n}=6)$

\begin{tabular}{lccccc}
\hline & \multicolumn{2}{c}{$0.5 \mathrm{mg} / \mathrm{kg}$} & & \multicolumn{2}{c}{$1 \mathrm{mg} / \mathrm{kg}$} \\
\cline { 2 - 3 } \cline { 5 - 6 } PI & Mean (\%) & RSD (\%) & & Mean (\%) & RSD (\%) \\
\hline Irgacure 184 & 91.4 & 1.6 & & 86.9 & 4.9 \\
Benzophenone & 82.9 & 1.2 & & 82.1 & 4.3 \\
Irgacure 651 & 85.7 & 1.5 & & 81.9 & 5.0 \\
Irgacure 907 & 84.2 & 1.1 & & 82.1 & 4.1 \\
Quantacure ITX & 80.9 & 3.3 & & 78.4 & 2.8 \\
Quantacure EHA & 75.2 & 5.3 & & 75.0 & 6.7 \\
\hline
\end{tabular}

0; 9H-thioxanthen-9-one, 2-(1-methylethyl)-(9CI)] and Quantacure EHA [CAS no. 21245-02-3; benzoic acid, 4(dimethylamino)-, 2-ethylhexyl ester (9CI)]. Irgacure and Quantacure are trademarks of CIBA, Basel, Switzerland. All of these PI (purity 99\%) were supplied by Aldrich (Madrid, Spain). Acetonitrile (ACN) and hexane were purchased from Merck (Darmstadt, Germany). Ultrapure water was prepared using a Milli-Q filter system (Millipore, Bedford, MA).

A primary stock solution of each PI $(1.0 \mathrm{mg} / \mathrm{mL})$ was prepared in ACN $(1.0 \mathrm{mg} / \mathrm{mL})$. Subsequent dilutions were prepared in ACN in the range of 0.1 to $10.0 \mu \mathrm{g} / \mathrm{mL}$ for the HPLC-UV calibration curves. Each calibration curve consisted of a plot of peak area of each PI against the concentration of the standard calibration solutions.

Solutions were stored in a refrigerator $\left(5^{\circ} \mathrm{C}\right)$ in glass bottles and they were stable during the period of study.

\section{Extraction Procedure}

Infant Formula. Infant formula was bought in different supermarkets on different dates and other products were kindly supplied by the packaging or food industries. Milk in tetra-brick packages was stored at room temperature and was analyzed immediately after opening. Milk extraction $(10 \mathrm{~mL})$ was carried out with $1.5 \mathrm{~mL}$ of ammoniac and $2 \times 20 \mathrm{~mL}$ of hexane. The supernatant was evaporated to dryness in a rotary evaporator and the residue was reconstituted with 10 $\mathrm{mL}$ of ACN.

Dairy Product Packaging. Dairy product packages $(\mathrm{n}=26)$ were analyzed in duplicate. Each food package was cut, and approximately $1 \mathrm{~g}$ of each was weighed and extracted with $10 \mathrm{~mL}$ of ACN during $24 \mathrm{~h}$ at $70^{\circ} \mathrm{C}$. Samples were then filtered before chromatographic analysis.

Table 3. Summary of the results for 6 photoinitiators in dairy food packaging materials

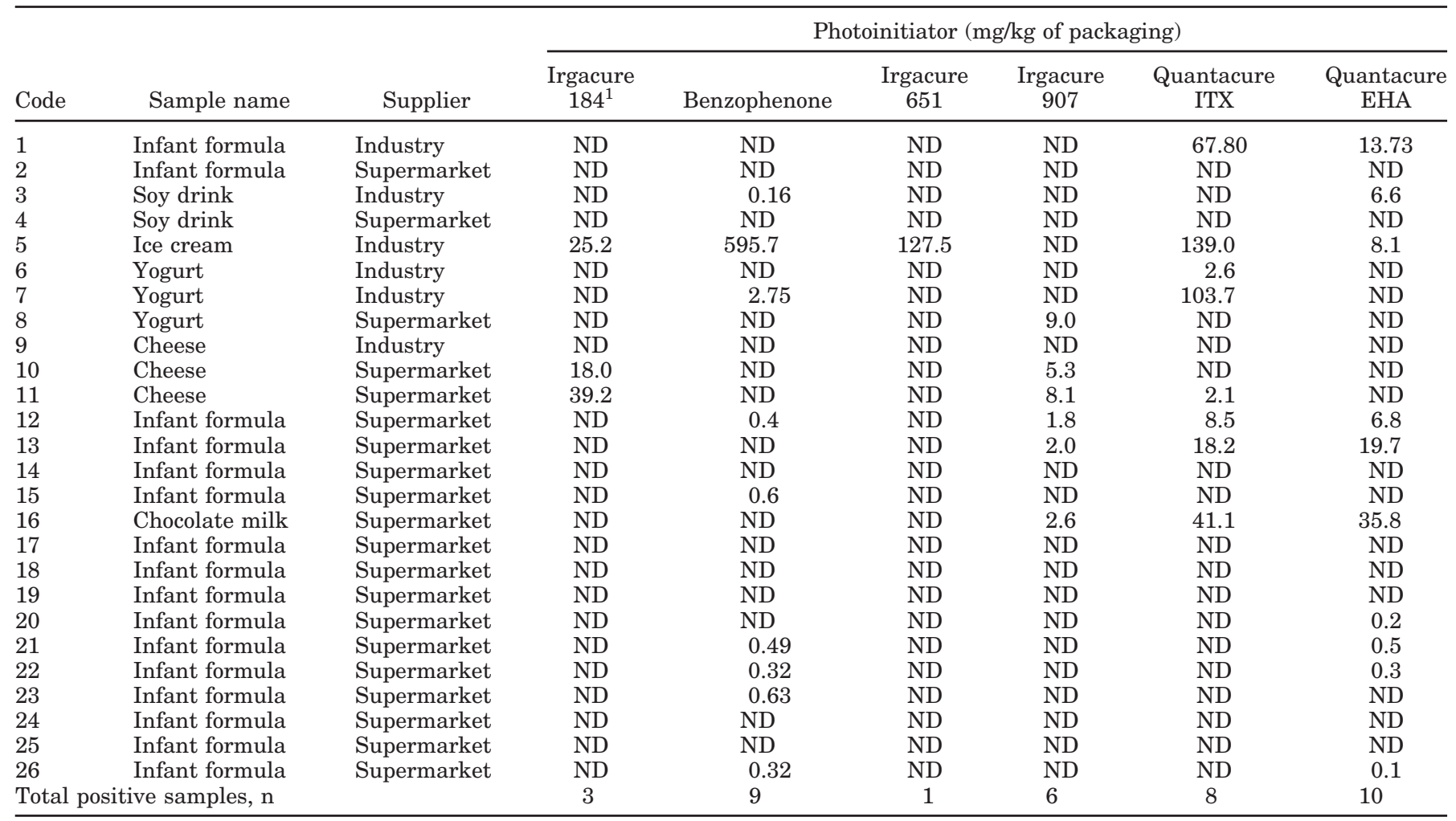

${ }^{1} \mathrm{ND}=$ not detectable. 


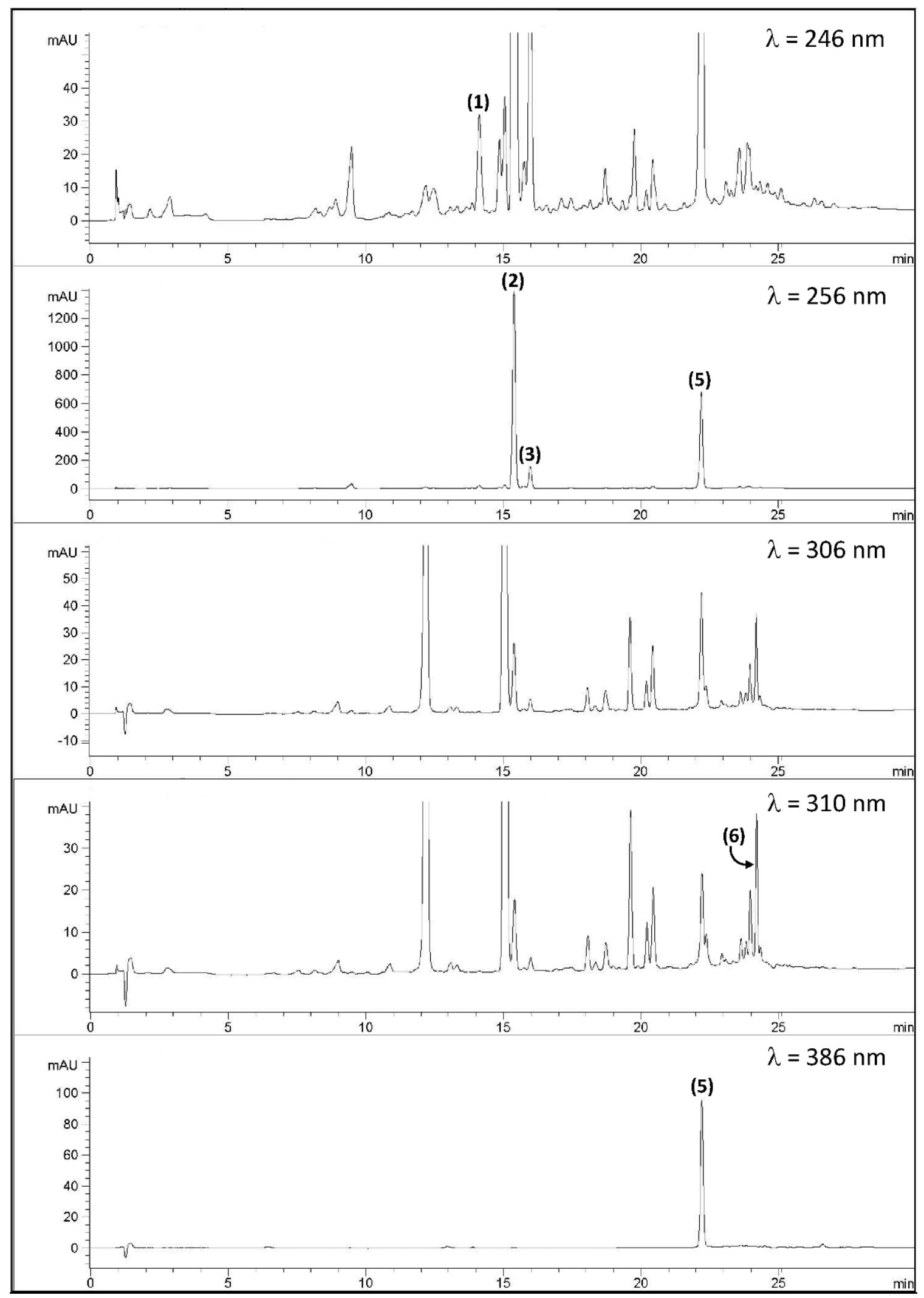

Figure 2. High-performance liquid chromatogram of a packaging sample contaminated with 5 of the 6 studied photoinitiators. $\mathrm{mAU}=$ milli-arbitrary units. Peaks: 1 = Irgacure 186; 2 = benzophenone; 3 = Irgacure 651; 4 = Irgacure 907; 5 = Quantacure ITX; 6 = Quantacure EHA. 
Table 4. Concentration of select photoinitiators in milk

\begin{tabular}{lcc}
\hline & \multicolumn{2}{c}{ Photoinitiator $(\mu \mathrm{g} / \mathrm{kg}$ of food $)$} \\
\cline { 2 - 3 } Sample code & Quantacure ITX & Quantacure EHA \\
\hline 12 & 65.42 & 213.74 \\
13 & 37.32 & 77.61 \\
16 & 213.24 & $\mathrm{ND}^{1}$ \\
\hline
\end{tabular}

${ }^{1} \mathrm{ND}=$ not detectable.

\section{Chromatographic Conditions}

HPLC-UV. The separation was achieved on a Kromasil $100 \mathrm{C} 18(15 \mathrm{~cm} \times 0.4 \mathrm{~cm}$ i.d., $5-\mu \mathrm{m}$ particle size $)$ analytical column from Teknokrom (Barcelona, Spain). The mobile phase was 20\% ACN:80\% water in the first 2 min, and then ACN was gradually increased to reach $80 \% \mathrm{ACN}: 20 \%$ water at $20 \mathrm{~min}$ and $100 \% \mathrm{ACN}$ at 23 $\mathrm{min}$. The total run time of each analysis was $30 \mathrm{~min}$ to ensure cleaning of the column between samples. The flow rate was $1.0 \mathrm{~mL} / \mathrm{min}$ and the injection volume was $50 \mu \mathrm{L}$. The HPLC system (Hewlett-Packard, Waldbronn, Germany) was fitted with a HP1100 quaternary pump, a degassing device, an autosampler, a column thermostatting system, and a diode array UV detector. The detector was continuously performing a scan in the range of 190 to $400 \mathrm{~nm}$. No reference wavelength was used and the band width used was $4 \mathrm{~nm}$ for both wavelengths. Irgacure 184 was detected at $246 \mathrm{~nm}$, benzophenone and Irgacure 651 were detected at $256 \mathrm{~nm}$, Irgacure 907 was detected at $306 \mathrm{~nm}$, Quantacure EHA was detected at $310 \mathrm{~nm}$, and Quantacure ITX was detected at $386 \mathrm{~nm}$. Photoinitiators were identified by comparison of their retention time and UV spectra with those of an injected pure standard using the same HPLC conditions.

HPLC-MS. An Agilent 1100 series HPLC coupled with an electrospray source, and a TOF (time of flight) analyzer (mass detector) (BioTOF II, Bruker, Billerica, MA) was used to confirm the identity of PI peaks.

The column used was a Zorbax Eclipse XDB C18 4.6 $\times 150 \mathrm{~mm}, 5 \mu \mathrm{m}$ with a C18 precolumn (Agilent Zorbax, Surplus Lab Inc., Muskegon, MI) set at $30^{\circ} \mathrm{C}$. The mobile phase was A: water with $0.2 \%$ formic acid and B: acetonitrile with $0.1 \%$ formic acid. The flow rate was 1 $\mathrm{mL} / \mathrm{min}$ and the solvent gradient was $20 \% \mathrm{~B}$ at $0 \mathrm{~min}$; $20 \% \mathrm{~B}$ at $2 \mathrm{~min} ; 80 \% \mathrm{~B}$ at $20 \mathrm{~min} ; 100 \% \mathrm{~B}$ at $23 \mathrm{~min}$; $100 \% \mathrm{~B}$ at $30 \mathrm{~min} ; 100 \% \mathrm{~B}$ at $36 \mathrm{~min} ; 20 \% \mathrm{~B}$ at 38 $\mathrm{min}$. The analytical column was equilibrated for $15 \mathrm{~min}$ between samples to obtain a stable baseline for subsequent analysis. The injection volume was $50 \mu \mathrm{L}$.

The detector (MS) operated under the following conditions: electrospray ionization interface operating in positive mode; source temperature: $200^{\circ} \mathrm{C}$, capillary:
$-4,500 \mathrm{~V}$, nebulizer pressure: $400 \mathrm{kPa}$, dry gas: $11 \mathrm{~L} /$ $\min$.

\section{RESULTS AND DISCUSSION}

\section{Food and PI Selection}

Milk was selected to carry out this study because ITX has been detected in this food matrix (Morlock and Schwack, 2006; Rothenbacher, 2007; Sun et al., 2007). Samples were purchased in 3 of the countries where ITX has also been detected (Portugal, Spain, and Italy). We decided to optimize a multimethod for the determination of 5 other PI besides ITX. Selected substances were Irgacure 184, benzophenone, Irgacure 651, Irgacure 907, Quantacure ITX, and Quantacure EHA.

\section{Extraction and Chromatographic Method Optimization}

Several extraction procedures were tested. First, extraction with $10 \mathrm{~mL}$ of ACN was tested and then extraction with $10 \mathrm{~mL}$ of hexane. Because milk tends to emulsify, 2 other procedures were tested: milk acidification to $\mathrm{pH} 4.6$ and addition of ammoniac. The best results, regarding recovery, were achieved with ammoniac and therefore this was the selected procedure.

Regarding HPLC method, several solvent gradients were tested. Best results were achieved using ACN/ water and starting the gradient with $20 \%$ ACN: $80 \%$ water. Figure 1 shows an HPLC chromatogram of a standard $(1 \mathrm{mg} / \mathrm{kg})$. As can be observed, good separation was achieved.

\section{HPLC Method Validation}

The linearity of the 6 PI was evaluated constructing calibration curves with 7 calibration levels $(0.1,0.5,1$, $2,5,7$, and $10 \mathrm{mg} / \mathrm{kg}$ ). Equation curves obtained were the following: $\mathrm{y}=56.87 \times 1.18$ for Irgacure $184, \mathrm{y}=$ $112.85 \times 3.50$ for benzophenone, $\mathrm{y}=52.76 \times 2.00$ for Irgacure $651, \mathrm{y}=72.56 \times 1.92$ for Irgacure 907, y = $28.02 \times 0.27$ for Quantacure ITX and $y=11.75 \times 4.60$ for Quantacure EHA. Correlation coefficients were always high $(\geq 0.9999)$. Detection and quantification limits were defined according to the guidelines of the American Chemical Society (1980). Limit detection values were $\geq 30 \mathrm{ng} / \mathrm{mL}$. In the case of ITX, limits are higher than those reports by others authors (see Table 1) because the techniques used were more sensitive. Nevertheless, the limit of detection (LD) for ITX (30 $\mu \mathrm{g} / \mathrm{L}$ of milk) is lower than those reported for the same technique and matrix in another study $(\geq 50 \mathrm{~g} / \mathrm{kg} ;$ Morlock and Schwack, 2006). 


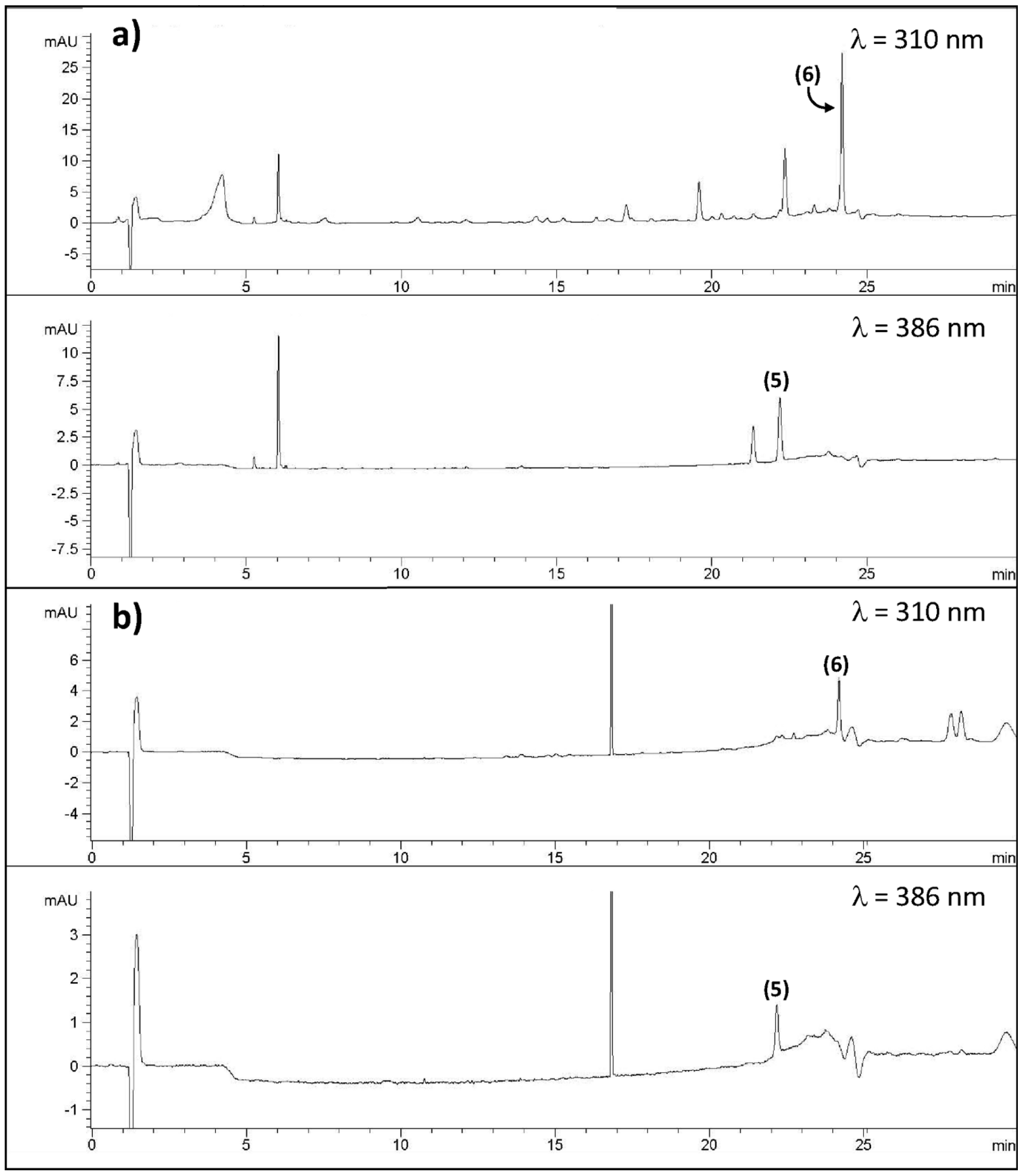

Figure 3. High-performance liquid chromatography-UV chromatogram of (A) sample milk packaging and (B) milk (sample 12). mAU = milli-artibrary units. Peaks: 5 = Quantacure ITX; 6 = Quantacure EHA. 


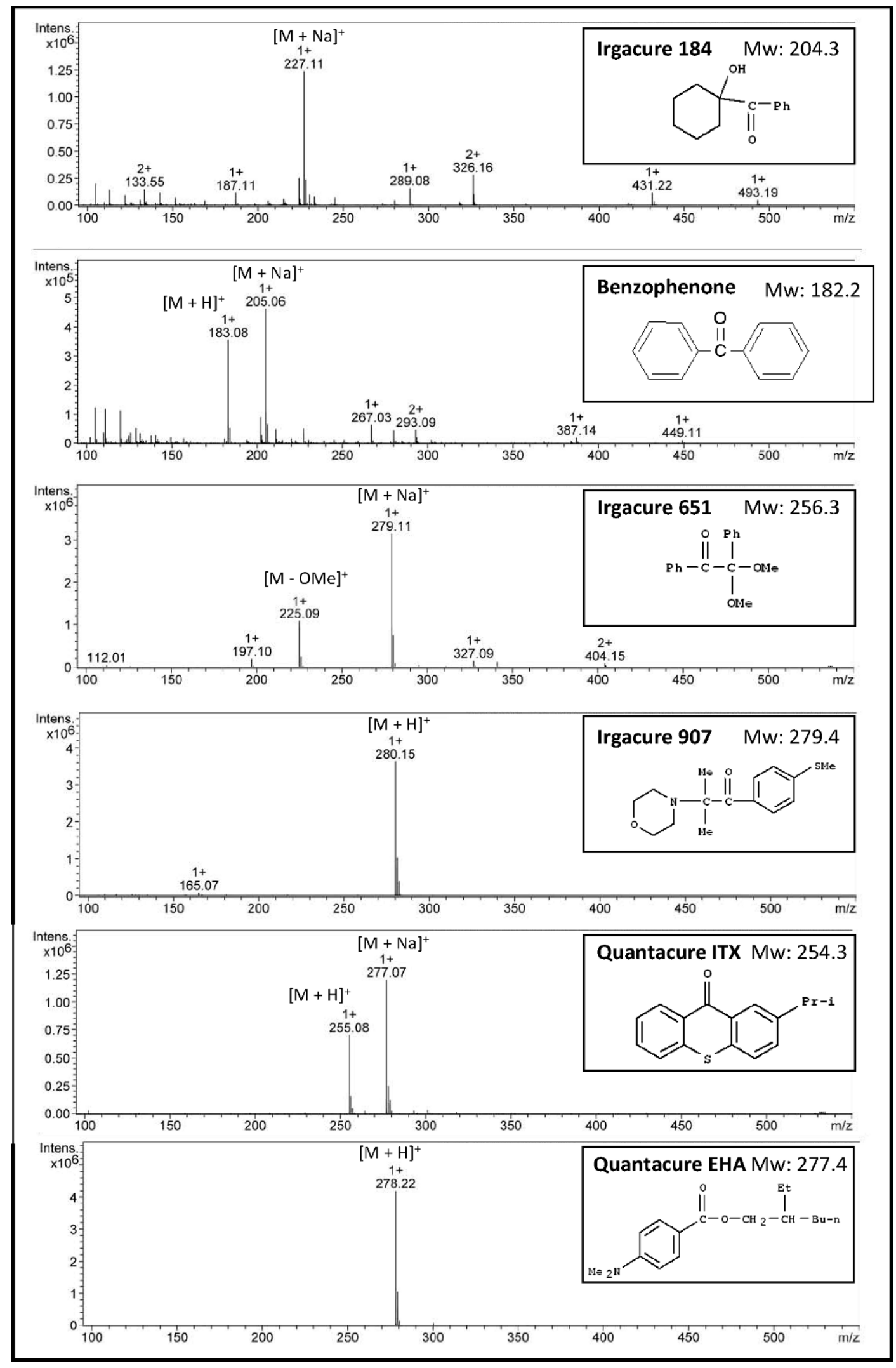

Figure 4. Mass spectra of the 6 photoinitiators. 
In regard to benzophenone, the LD was $20 \mu \mathrm{g} / \mathrm{kg}$, which was similar to that found by Anderson and Castle (2003; $0.01 \mathrm{mg} / \mathrm{kg}$ ), who analyzed cartonboard packaging materials by GC-MS.

Recovery was tested using a standard addition procedure. Before the recovery study, the milk sample used for fortification was analyzed separately to check that natural components of the sample do not interfere in analytical determination of PI. Six samples of orange juice were spiked before extraction with a solution containing the 6 PI. Recoveries were determined at 1 and $0.5 \mathrm{mg} / \mathrm{kg}$ and are shown in Table 2 . Recoveries were satisfactory and ranged from 80.9 to $91.4 \%$ at $0.5 \mathrm{mg} /$ $\mathrm{kg}$ and 78.4 to $86.9 \%$ at $1 \mathrm{mg} / \mathrm{kg}$, except for Quantacure EHA $(75.2 \%$ at $0.5 \mathrm{mg} / \mathrm{kg}$ and $75.0 \%$ at $1 \mathrm{mg} / \mathrm{kg})$. The residual standard deviation ranged in all samples from 1.0 to $6.7 \%$.

\section{Analysis of Samples}

Twenty-six commercial dairy products packages were analyzed. A third of the packaging samples gave negative results for all PI. Three were positive for Irgacure 184, 9 for benzophenone, 1 for Irgacure 651, 6 for Irgacure 907, 8 for Quantacure ITX, and 10 for Quantacure EHA (Table 3). Figure 2 shows the HPLC chromatogram of a packaging sample contaminated with 5 of the 6 studied PI.

Milk samples whose packages gave positive results for some PI were also analyzed. Three of them were positive, 2 of them for both Quantacure ITX and Quantacure EHA and 1 for Quantacure EHA only. Results are shown in Table 4.

Six replicates of a milk sample positive for Quantacure ITX and EHA were subjected to the extraction protocol. Figure 3 shows the HPLC-UV chromatogram of this sample (A is sample milk packaging, $\mathrm{B}$ is a milk sample). Good repeatability was achieved for both PI (residual $\mathrm{SD}=3.9 \%$ for ITX and $8.8 \%$ for EHA).

\section{Analysis by HPLC-MS}

Analysis by HPLC-MS was used to confirm the HPLC-UV results. First, a standard PI solution was injected under conditions described in Materials and Methods. Figure 4 shows the full scan mass spectra of the 6 selected PI obtained. For Irgacure 184, the most abundant fragment was the sodium adduct $[\mathrm{M}+\mathrm{Na}]^{+}$ at $m / z 227$. For benzophenone, the most abundant fragments were $m / z 183$ and 205, which correspond to the sodium adduct $[\mathrm{M}+\mathrm{Na}]^{+}$and the protonated molecule $[\mathrm{M}+\mathrm{H}]^{+}$, respectively.

Concerning Irgacure 651, the most abundant fragments were $\mathrm{m} / z 279$ and 225 . The first corresponds to the sodium adduct $[\mathrm{M}+\mathrm{Na}]^{+}$and the second to the molecule without $\mathrm{OMe},[\mathrm{M}-\mathrm{OMe}]^{+}$. In regard to Irgacure 907 and Quantacure EHA, the most abundant fragment was the protonated molecule $[\mathrm{M}+\mathrm{H}]^{+}$at $\mathrm{m} /$ $z 280$ and 278, respectively. For Quantacure ITX, the most abundant fragments were $m / z 277$ and 255, which correspond to the sodium adduct $[\mathrm{M}+\mathrm{Na}]^{+}$and the protonated molecule $[\mathrm{M}+\mathrm{H}]^{+}$, respectively. The sodium adduct, which was an abundant fragment for Irgacure 184, benzophenone, Irgacure 651, and Quantacure ITX, is typical of molecules that have oxygen or hydroxyl atoms with a pair of electrons and it is caused by traces of $\mathrm{Na}^{+}$that can be found in the HPLC system (e.g., solvents, tubes; Sagratini et al., 2006).

All positive samples were injected by HPLC-MS and results were confirmed by comparison of mass spectra of standards and samples.

\section{CONCLUSIONS}

The method described is a good alternative analytical tool for the routine determination of these PI in packaging and milk samples. Analysis by HPLC-electrospray ionization-time of flight is an appropriate and useful method for positive identification of the 6 PI.

\section{ACKNOWLEDGMENTS}

The study was financially supported by the Xunta de Galicia (Proj. no. PGIDIT05TAL20301PR). The authors are grateful to the "Ramón y Cajal" program financed by the Ministry of Education of Spain and to the "Fundação para a Ciência e Tecnologia", Portugal, for the postdoctoral fellowship of Ana Sanches Silva. The authors are grateful to Patricia Blanco Carro and Gonzalo Hermelo Vidal for their excellent technical assistance and to Monica Paz Tarrio and Esteban Guitián Fernández for their assistance with HPLC-MS analyses.

\section{REFERENCES}

American Chemical Society. 1980. Guidelines for data acquisition and data quality evaluation in environmental chemistry. ACS Committee on Environmental Improvement. Anal. Chem. 52:2242-2249.

Anderson, W. A. C., and L. Castle. 2003. Benzophenone in cartonboard packaging materials and the factors that influence its migration into food. Food Addit. Contam. 20:607-618.

Bradley, G. 2006a. Photoinitiators for coatings applications, part 1A brief overview. Coatings and Inks. http://www.specialchem4 coatings.com/resources/articles/article. aspx?id=5521 Accessed Jan. 23, 2008.

Bradley, G. 2006b. Photoinitiators for coatings applications, part 2Which photoinitiator to choose? Coatings and Inks. http://www. specialchem4coatings.com/resources/articles/article.aspx?id= 6238 Accessed Jan. 23, 2008.

Bradley, G. 2007. Photoinitiators for coatings applications, part 3What's new or may be coming? Coatings and Inks. http://www. 
specialchem4coatings.com/resources/articles/article.aspx?id= 6604 Accessed Jan. 23, 2008.

European Food Safety Authority (EFSA). 2005a. EFSA provides advice on the safety of ITX: ITX considered of low health concern. http://www.efsa.europa.eu/EFSA/News_PR/pr_dir_itxsafety_ en2.pdf

European Food Safety Authority (EFSA). 2005b. Opinion of the Scientific Panel of Food Additives, Flavourings, Processing Aids and materials in contact with foods (AFC) on a request from the Commission related to 2-isopropyl thioxanthone (ITX) and 2-ethylhexyl-4-dimethylaminobenzoate (EHDAB) in food materials. EFSA J. 293:1-15. http://www.efsa.europa.eu/EFSA/Scientific_ Opinion/afc_op_ej293_it x_opinion_en1.pdf

European Union. 2004. Regulation (EC) 1935/2004 of the European Parliament and of the Council of 27 October 2004 on Materials and Articles Intended to Come into Contact with Food and Repealing Directives 80/590/EEC and 89/109/EEC. Off. J. L 338:4-18.

Morlock, G., and W. Schwack. 2006. Determination of isopropylthioxanthone (ITX) in milk, yoghurt and fat by HPTLC-FLD, HPTLCESI/MS and HPTLC-DART/MS. Anal. Bioanal. Chem. 385:586-595.
Papilloud, S., and D. Baudraz. 2002a. Migration tests for substracts printed with UV ink systems in aqueous simulants. Prog. Org. Coatings 45:231-237.

Papilloud, S., and D. Baudraz. 2002b. Analysis of food packaging UV inks for chemicals with potential to migrate into food simulants. Food Addit. Contam. 19:168-175.

Rapid Alert System for Food and Feed (RASFF). 2005. Annual Report, no. 170/2002. http://ec.europa.eu/food/food/rapidalert/report 2005_en.pdf

Rothenbacher, T., M. Baumann, and D. Fugel. 2007. 2-Isopropylthioxanthone (2-ITX) in food and food packaging materials on the German market. Food Addit. Contam. 24:438-444.

Sagratini, G., J. Mañes, D. Giardiná, and Y. Pico. 2006. Determination of isopropyl thioxanthone (ITX) in fruit juices by pressurized liquid extraction and liquid chromatography-mass spectrometry. J. Agric. Food Chem. 54:7947-7952.

Sun, C., S. H. Chan, D. Lu, H. M. W. Lee, and B. C. Bloodworth. 2007. Determination of isopropyl-9H-thioxanthen-9-one in packaged beverages by solid-phase extraction clean-up and liquid chromatography with tandem mass spectrometry detection. J. Chromatogr. A. 1143:162-167. doi:10.1016/j.chroma.2007.01.014 